\title{
Determinants of insulin sensitivity in chronic heart failure
}

\author{
L.W.E. Sabelis ${ }^{\mathrm{a}, *}$, P.J. Senden ${ }^{\mathrm{c}}$, M.L. Zonderland ${ }^{\mathrm{a}}$, A. van de Wiel ${ }^{\mathrm{d}}$, J.P.M. Wielders ${ }^{\mathrm{e}}$, I.A. Huisveld ${ }^{\mathrm{a}}$, \\ T.W. van Haeften ${ }^{\mathrm{b}}$, W.L. Mosterd ${ }^{\mathrm{a}, \mathrm{c}}$ \\ ${ }^{a}$ Department of Sports Medicine, University Medical Center Utrecht, Utrecht, The Netherlands \\ ${ }^{\mathrm{b}}$ Department of Internal Medicine, University Medical Center Utrecht, Utrecht, The Netherlands \\ ${ }^{\mathrm{c}}$ Department of Cardiology, Meander Medical Center, Amersfoort, The Netherlands \\ ${ }^{\mathrm{d}}$ Department of Internal Medicine, Meander Medical Center, Amersfoort, The Netherlands \\ ${ }^{\mathrm{e}}$ Department of Laboratory Medicine, Meander Medical Center, Amersfoort, The Netherlands
}

Received 2 April 2003; received in revised form 8 May 2003; accepted 31 July 2003

\begin{abstract}
Objective: To describe the determinants of insulin sensitivity (IS) in chronic heart failure (CHF), we created a model in which the influence of lifestyle factors and etiology of heart failure on IS were incorporated concomitantly with age, left ventricular ejection fraction (LVEF) and parameters of body composition. Design: Observational cohort study. Setting: Outpatient clinic for chronic heart failure. Patients: Fifty-seven male CHF patients [NYHA class II-III, age $61 \pm 9$ years, body mass index (BMI) $26.9 \pm 3.3 \mathrm{~kg} / \mathrm{m}^{2}$ (mean \pm S.D.) ]. Interventions: Euglycemic hyperinsulinemic clamp, cycle ergometry, anthropometric measurements, LVEF and a physical activity questionnaire. Main outcome measures: A model explaining the variance of IS in CHF. Results: IS was $18.2 \pm 8.6 \mu \mathrm{g} \cdot \mathrm{kg}^{-1} \cdot \mathrm{min}^{-1} \cdot \mathrm{mU}^{-1} \cdot 1^{-1}$, fasting insulin level was $15.9 \pm 11.0 \mathrm{mU} / 1$ and fasting glucose level was $5.5 \pm 0.6 \mathrm{mmol} / \mathrm{l}$. Peak $\dot{V}_{\mathrm{O}_{2}}$ was $19.1 \pm 4.9 \mathrm{ml} \cdot \mathrm{kg}^{-1} \cdot \mathrm{min}^{-1}$ and LVEF $26.2 \pm 7.1 \%$. IS was inversely associated with fasting insulin concentration $(r=-0.50, P<0.001)$ and BMI $(r=-0.54, P<0.001)$. After controlling for BMI, IS also revealed a correlation with age $(r=-0.36, P<0.01)$. The model explained $60 \%$ of variance in IS: BMI contributed $20 \%$, smoking $17 \%$, age $17 \%$ and physical activity in daily life (DPA) $16 \%$ (all $P<0.05)$ to the variance of IS, whereas LVEF $(9 \%)$ and etiology of heart failure $(8 \%)$ contributed moderately. Conclusions: In CHF patients, IS is for a major part predicted by BMI, smoking, age, daily physical activity, LVEF and etiology of heart failure.
\end{abstract}

(C) 2003 European Society of Cardiology. Published by Elsevier B.V. All rights reserved.

Keywords: Chronic heart failure; Insulin sensitivity; Exercise tolerance

\section{Introduction}

The most impairing symptom for patients suffering from chronic heart failure (CHF) is a decreased exercise tolerance manifested by dyspnea and fatigue. The underlying mechanism for the decrease in exercise tolerance is not fully understood. There is no correlation between left ventricular ejection fraction (LVEF) or other central hemodynamic factors, such as intra cardiac pressures and exercise tolerance [1,2]. This suggests that other factors than cardiac output alone must limit exercise tolerance in CHF patients. One possibility could, there-

\footnotetext{
*Corresponding author. Tel.: +31-30-253-8925; fax: +31-30-2539036.

E-mail address: 1.w.esabelis@med.uu.nl (L.W.E. Sabelis).
}

fore, be that the underlying mechanism for the decrease in exercise tolerance is situated in the skeletal muscles [3]. Characteristic changes in peripheral tissues are indeed found; such as a decreased peripheral blood flow [4] and a disturbed anabolic/catabolic balance [5]. Insulin sensitivity (IS) is often impaired in CHF [6] and has been considered an important factor in this concept $[3,7]$ because of the hemodynamic $[8,9]$ and anabolic characteristics of insulin.

IS is found to be related to several factors. In healthy people, smoking is known to be associated with a decrease in IS [10], while BMI (as a measure of obesity) $[11,12]$ and age [13] are negatively related to IS. Moreover, IS has been reported to be positively associated with peak oxygen uptake (peak $\dot{V}_{\mathrm{O}_{2}}$ ) in healthy 
subjects and CHF patients $[6,14,15]$ and with sports participation in first-degree relatives of type 2 diabetes patients [16]. IS in patients suffering from CHF, as a result of idiopathic cardiomyopathy, was higher than in patients with ischemic etiology [6]. BMI and peak $\dot{V}_{\mathrm{O}_{2}}$ are the two main determinants of IS in young healthy subjects [17].

Most of the reported studies refer to simple bivariate associations between IS and the previously mentioned variables, suggesting that all determinants operate independently. The aim of the present study was to determine the relative importance of various factors, which have previously been proposed to relate to IS in CHF patients. Therefore, we determined insulin sensitivity, LVEF, exercise tolerance and anthropometric variables in a large group of male CHF patients; we also assessed physical activity in daily life (DPA) by questionnaire.

\section{Patients and methods}

\subsection{Patients}

Fifty-seven male CHF patients in NYHA class II or III, aged 40-70, participated in the study. Diagnosis of CHF was mainly based on medical history of exertional dyspnea, muscle fatigue and/or fluid retention and diminished LVEF.

Inclusion criteria were: a history of CHF longer than 6 months, classified as NYHA class II/III, with a LVEF of less than $35 \%$. Exclusion criteria were: interfering diseases such as COPD, fasting glucose level of more than $7.0 \mathrm{mmol} / 1$ (impaired fasting glucose) or neuromuscular disorders and hypertension (blood pressure higher than $170 \mathrm{mmHg}$ systolic and/or higher than 110 $\mathrm{mmHg}$ diastolic when on optimal anti-hypertensive therapy). All patients had to be clinically stable for 4 weeks before randomisation. The following criteria were used to asses the presence of ischemic heart disease as the cause of CHF: documented (as verified in hospital records) history or admission for acute coronary syndrome, electrocardiographic evidence of myocardial infarction, positive exercise test, echocardiographic evidence of segmental wall motion abnormalities, significant coronary artery lesions on angiography, myocardial infarction or ischemia demonstrated by nuclear imaging. If none of these conditions were met, the patients were considered to have idiopathic cardiomyopathy. The cause of CHF was ischemic heart disease in $62 \%$ of the patients and idiopathic cardiomyopathy in 38\%. Patients were recruited from the Meander Medical Center (Amersfoort). Since the objective of the study was to evaluate the role of IS as an etiological factor of CHF as the primary disease, and not CHF secondary to other diseases like diabetes mellitus (DM), patients suffering from DM were excluded. Forty-seven patients used ACE-inhibitors, 5 AT-II blockers, $24 \beta$-blockers and 29 loop diuretics. The average LVEF, which was determined by ultrasound (Simpson's formula) [18], was $26 \%$. During the study period, patients continued to use their medication.

\subsection{Methods}

\subsubsection{Body composition}

Percentage body fat was estimated from the sum of skinfolds, measured at four sites: triceps, biceps, subscapular and suprailiacal, according to Durnin and Womersley [19]. This method gives an appropriate measure of total body fatness. Fat mass (FM) was calculated from percentage body fat and total body weight. Fat free mass (FFM) was calculated from total body weight and FM. BMI was calculated in weight per height squared $\left(\mathrm{kg} / \mathrm{m}^{2}\right)$. In addition to body fat composition, body fat distribution was assessed using waist circumference (WC) [20], which was determined at the level of the umbilicus.

\subsubsection{Insulin sensitivity}

IS was assessed using an euglycemic hyperinsulinemic clamp (insulin infusion $3 \mathrm{mU} \cdot \mathrm{kg}^{-1} \cdot \mathrm{min}^{-1}, 180 \mathrm{~min}$ ) [21]. This method is regarded as the 'gold standard' for measuring insulin sensitivity [22]. Hematocrit was assessed three times during the clamp in order to convert blood glucose concentration into plasma glucose concentration, which was assessed at the bedside using a glucose analyser (YSI 2300 Stat, Yellow Springs, USA). Plasma insulin concentration was measured by chemiluminescence immunoassay (Immulite 1 analyser, DPC, Los Angeles, USA) with intra- and interassay coefficients of variation of $7.6 \%$ and $10.0 \%$, respectively.

IS was calculated by dividing the average glucose infusion rate (per kilogram body weight) by the average plasma insulin level during the 3rd hour of the clamp.

The HOMA index (homeostasis model assessment), a rough index of IS, was calculated as (fasting plasma glucose $\times$ fasting plasma insulin)/22.5. An index higher than 1.1 suggested an impaired insulin sensitivity [23].

\subsubsection{Exercise tolerance}

Exercise tolerance was determined by means of incremental cycle ergometry (Excalibur, Lode, Groningen, The Netherlands) with increments of $20 \mathrm{~W}$ every 3 min. The test was ended when the patient was restricted by symptoms or could not maintain a pedal frequency of $65 \mathrm{rev} / \mathrm{min}$.

Ventilatory parameters were measured breath-bybreath (Oxycon B, Mijnhart-Jaeger, Bunnik, The Netherlands). Data were recorded at $15 \mathrm{~s}$ intervals and respiratory exchange ratios and ventilatory equivalents for $\mathrm{O}_{2}$ and $\mathrm{CO}_{2}$ were calculated. Peak workload was defined as the sum of the last completed 3-min workload plus the time corrected contribution of the final uncom- 
pleted workload. Peak exercise tolerance was expressed as oxygen uptake at peak exercise (peak $\dot{V}_{\mathrm{O}_{2}}$ ), calculated as the mean of the values during the final $30 \mathrm{~s}$ of exercise.

\subsubsection{Physical activity questionnaire}

To assess daily physical activity (DPA) the modified Baecke questionnaire for physical activity in elderly people was used. This questionnaire has been validated for the Dutch elderly population [24]. The questionnaire consisted of scores in household activities, sports activities and other leisure time activities; added up to give the DPA score. Items on household activities were questions with four to five possible ratings, ranging from very active to inactive. Sports and 'other activity' scores were calculated from type of activity, duration and period of the year in which the activity was normally performed. All activities were classified according to work, posture and movements. An intensity code was used to classify each type of activity. The higher the activity score the more active was the patient. The questionnaire took approximately $15 \mathrm{~min}$ to complete.

\subsection{Statistical standards}

Statistical analysis was performed with SPSS for Windows version 10.0.

Log transformed values were used for statistical analysis of fasting insulin levels, HOMA-index, and DPA score. Simple bivariate relationships were calculated using Pearson's correlation coefficient or Spearman's rho. To test for differences between groups, one-way ANOVA was used. To determine the contribution of several variables to the variance of IS, univariate general linear model analysis (pairwise) was used.

A probability value of $P \leq 0.05$ was considered significant. Data are given as mean \pm S.D.

\subsection{Ethical standards}

The study was approved by the Medical Ethics Committees of the UMC Utrecht and The Meander Medical Center Amersfoort, The Netherlands. All patients signed written informed consent. The investigation conforms with the principles in the Declaration of Helsinki ( $\mathrm{Br}$ Med J 1964;ii:177).

\section{Results}

No complications occurred during any of the tests.

\subsection{Baseline characteristics}

Baseline data are summarised in Table 1. The mean values for BMI of $26.9 \mathrm{~kg} / \mathrm{m}^{2}$, body fat of $33 \%$ and WC of $100.5 \mathrm{~cm}$ indicate that this patient group is
Table 1

Baseline characteristics

\begin{tabular}{lc}
\hline & Mean \pm S.D. \\
\hline Age $($ years $)$ & $61 \pm 9$ \\
BMI $\left(\mathrm{kg} / \mathrm{m}^{2}\right)$ & $26.9 \pm 3.3$ \\
Body fat $(\%)$ & $33.5 \pm 4.9$ \\
Waist circumference $(\mathrm{cm})$ & $100.5 \pm 8.9$ \\
Daily physical activity score & $13 \pm 9$ \\
Left ventricular ejection fraction $(\%)$ & $26.2 \pm 7.1$ \\
Left ventricular end-diastolic diameter $(\mathrm{mm})$ & $66.6 \pm 9.4$ \\
Fasting glucose $(\mathrm{mmol} / \mathrm{l})$ & $5.5 \pm 0.6$ \\
Fasting insulin $(\mathrm{mU} / \mathrm{l})$ & $15.9 \pm 11.1$ \\
$\mathrm{HOMA-index}$ & $3.9 \pm 2.7$ \\
IS $\left(\mu \mathrm{g} \cdot \mathrm{kg}^{-1} \cdot \mathrm{min}^{-1} \cdot \mathrm{mU}^{-1} \cdot \mathrm{l}^{-1}\right)$ & $18.2 \pm 8.6$ \\
Fasting triglyceride $(\mathrm{mmol} / \mathrm{l})$ & $1.6 \pm 0.9$ \\
Fasting HDL-cholesterol $(\mathrm{mmol} / \mathrm{l})$ & $1.2 \pm 0.3$ \\
Fasting LDL-cholesterol $(\mathrm{mmol} / \mathrm{l})$ & $3.3 \pm 1.0$ \\
\hline
\end{tabular}

closer to overweight than underweight. On average, non-smokers had a $13 \%$ higher BMI than smokers $\left(27.7 \pm 3.2\right.$ vs. $24.6 \pm 2.5 \mathrm{~kg} / \mathrm{m}^{2}$, one-way ANOVA, $P<$ $0.01)$.

Fasting glucose levels were within normal limits $(<7.0 \mathrm{mmol} / \mathrm{l})$ [25], whereas fasting insulin levels were somewhat elevated according to in-house reference ranges $(<10 \mathrm{mU} / \mathrm{l})$. Ninety-one percent of patients presented with a HOMA-index of over 1.1 indicative of impaired IS.

The lipoprotein profile was within normal limits according to in-house reference ranges.

\subsection{Insulin sensitivity}

On average, IS was 30\% higher in patients with idiopathic cardiomyopathy vs. those with an ischemic etiology of heart failure $(20.9 \pm 11.5$ vs. $16.2 \pm 5.9$ $\mu \mathrm{g} \cdot \mathrm{kg}^{-1} \cdot \mathrm{min}^{-1} \cdot \mathrm{mU}^{-1} \cdot 1^{-1}$, one-way ANOVA, $P<$ $0.05)$. On average, smokers $(n=15)$ had a $52 \%$ higher IS than non-smokers $(n=44)(24.4 \pm 10.2$ vs. $16.0 \pm 6.9$ $\mu \mathrm{g} \cdot \mathrm{kg}^{-1} \cdot \mathrm{min}^{-1} \cdot \mathrm{mU}^{-1} \cdot 1^{-1}$, one-way ANOVA, $P<$ 0.01 ). Variables of glucose metabolism and IS were similar in patients who used B-blockers (selective or non-selective) compared with those who did not (oneway ANOVA, ns; Table 2).

As expected, simple bivariate correlations showed an inverse correlation of IS with fasting insulin concentration $(r=-0.50, P<0.001)$, BMI $(r=-0.54, P<0.001)$ and WC $(r=-0.54, P<0.001)$. After controlling for BMI, age also revealed a negative correlation with IS $(r=-0.36, P<0.01)$. IS showed a positive association with DPA $(r=0.31, P<0.05)$ and household score $(r=$ $0.41, P<0.01)$, but not with the sports score in the subgroup of 18 patients, which took part in sports activities. With regard to age, body composition, glucose metabolism and IS, this sub group was representative for the group as a whole. 
Table 2

Variables of glucose metabolism and insulin sensitivity in relation to (non-selective/selective) ß-blocker therapy

\begin{tabular}{lllll}
\hline $\begin{array}{l}\text { B-blockers } \\
(\mathrm{N})\end{array}$ & $\begin{array}{l}\text { Fasting glucose } \\
(\mathrm{mmol} / \mathrm{l})\end{array}$ & $\begin{array}{l}\text { Fasting insulin } \\
(\mathrm{mU} / \mathrm{l})\end{array}$ & HOMA-index & $\begin{array}{l}\text { IS } \\
\left(\mu \mathrm{gg}^{-1} \mathrm{~min}^{-1} \mathrm{mU}^{-1} \mathrm{l}^{-1}\right)\end{array}$ \\
\hline None (33) & $5.7 \pm 0.6$ & $15.7 \pm 10.9$ & $18.0 \pm 9.3$ \\
Non-selective (11) & $5.4 \pm 0.3$ & $11.3 \pm 6.2$ & $4.0 \pm 2.7$ & $20.4 \pm 9.0$ \\
Selective (13) & $5.3 \pm 0.7$ & $20.8 \pm 13.7$ & $2.7 \pm 1.5$ & $16.9 \pm 6.5$ \\
& $\mathrm{~ns}^{*}$ & $\mathrm{~ns}^{*}$ & $4.9 \pm 3.2$ & $\mathrm{~ns}^{*}$ \\
\end{tabular}

* One-way ANOVA with post hoc test, Bonferroni.

Table 3

Results of cycle ergometry

\begin{tabular}{lc}
\hline & Mean \pm S.D. \\
\hline Peak $\dot{V} \mathrm{O}_{2}(\mathrm{ml} / \mathrm{min})$ & $1606 \pm 451$ \\
Peak $\dot{V} \mathrm{O}_{2}$ per $\mathrm{kg}$ body w $\left(\mathrm{ml} \cdot \mathrm{kg}^{-1} \cdot \mathrm{min}^{-1}\right)$ & $19.1 \pm 4.9$ \\
Peak minute ventilation $(1 / \mathrm{min})$ & $64.9 \pm 14.9$ \\
Peak respiration quotient & $1.10 \pm 0.08$ \\
Ventilatory equivalent for $\mathrm{O}_{2}$ & $40.1 \pm 7.6$ \\
Peak workload (W) & $105 \pm 36$ \\
Peak heart rate (beats $/ \mathrm{min})$ & $143 \pm 28$ \\
\hline
\end{tabular}

No significant associations with exercise tolerance (expressed as peak $\dot{V}_{\mathrm{O}_{2}}$ ) or parameters of the lipoprotein profile, were found.

\subsection{Cycle ergometry}

Results of cycle ergometry are given in Table 3. Peak $\dot{V} \mathrm{O}_{2}$ per kilogram bodyweight $\left(\mathrm{ml} \cdot \mathrm{kg}^{-1} \cdot \mathrm{min}^{-1}\right)$ was $62 \pm 16 \%$ of predicted peak $\dot{V}_{\mathrm{O}_{2}}$ based on height, weight, sex and age according to Jones [26]. No difference in peak $\dot{V} \mathrm{O}_{2}$ or peak workload was found between patients who used $\beta$-blockers and those who did not, obviously peak heart rate was lower in $\beta$-blocker users $(132 \pm 24$ vs. $150 \pm 29$ beats/min, one-way ANOVA, $P<0.05)$.

Non-smokers had a $30 \%$ higher peak workload than smokers $(111 \pm 38$ vs. $86 \pm 18 \mathrm{~W}$, one-way ANOVA, $P<0.05)$. There was no difference in peak $\dot{V} \mathrm{O}_{2}$ or peak workload between patients with ischemic vs. idiopathic cardiomyopathic etiology of heart failure.

Peak $\dot{V} \mathrm{O}_{2}\left(\mathrm{ml} \cdot \mathrm{kg}^{-1} \cdot \mathrm{min}^{-1}\right)$ showed a positive association with daily physical activity $(r=0.39, P<0.01)$. The sports score related to peak $\dot{V}_{\mathrm{O}_{2}}$ in the sub group of 18 patients that took part in sports activities $(r=$ $0.59, P<0.05)$.

\subsection{Daily physical activity}

Daily physical activity score was $13 \pm 9$. This is lower than what was found in healthy elderly Dutch people [24]. Most patients predominantly participated in household activities, 18 patients took part in sports activities, varying from tennis to cardio-fitness.

Other activities undertaken by the patients were walking, gardening and cycling.

\subsection{Contribution of various parameters to insulin sensitivity}

The model showed that $60 \%$ of the variance of IS could be explained. BMI contributed 20\%, smoking $17 \%$, age $17 \%$ and DPA 16\%, (all $P<0.05$ ), whereas LVEF (9\%) and etiology of heart failure $(8 \%)$ contributed moderately (Fig. 1). When FM or percentage body fat was entered in the model instead of BMI, the explained variance did not change. But when BMI was replaced by FFM the explained variance decreased from

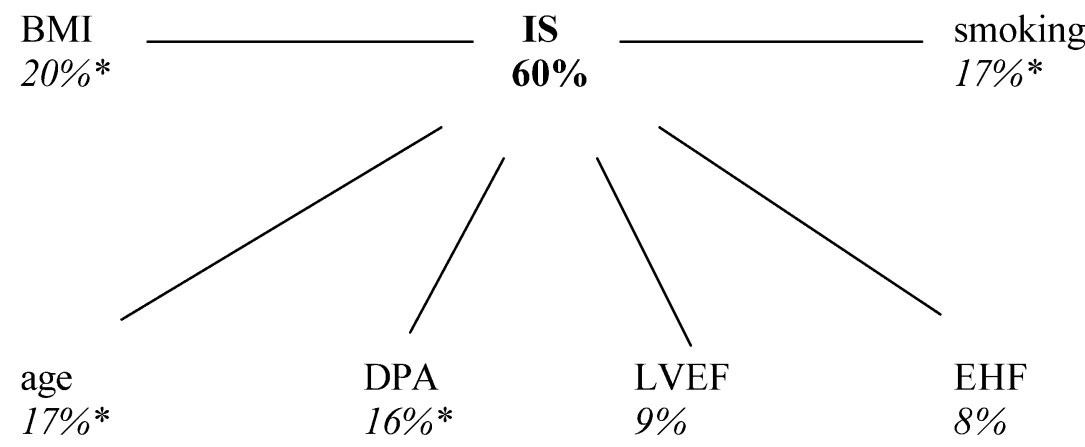

Fig. 1. Determinants of insulin sensitivity (IS) in CHF. Total explained variance (adjusted $R^{2}$ ) is $60 \%$; contributions of individual determinants (adjusted for the influence of the other determinants) are depicted in italic. DPA = daily physical activity, LVEF=left ventricular ejection fraction, $\mathrm{EHF}=$ etiology of heart failure. ${ }^{*} P \leq 0.05$. 
60 to $51 \%$. Exercise tolerance (peak $\dot{V}_{\mathrm{O}_{2}}$ ) and use of $\beta-$ blockers, either selective or non-selective, did not add to the explained variance of IS. On the contrary, adding these variables lead to a decrease in explained variance. None of the parameters of the lipoprotein profile added to the explained variance of the model.

\section{Discussion}

In the present study, we described the determinants of IS in CHF. To obtain more detailed insight into the role of IS in CHF, we created a model in which the influence of lifestyle factors and etiology of heart failure on IS were incorporated concomitantly with age, LVEF and parameters of body composition.

As expected, IS correlated negatively with fasting plasma insulin, age and BMI, a measure of obesity. Since obesity is known to lead to insulin resistance, and will (normally) lead to increased pancreatic insulin secretion, these findings underscore the validity of the clamp technique used in this study [11,12]. From a 'metabolic' point of view, a high BMI, which is associated with lower IS and other cardiovascular disease risk factors (hypertension and dyslipidemia) [27], is not favourable. This seems paradoxical, since elevated BMI is an independent predictor of improved survival in CHF patients [28]. It might be suggested that the U-shaped association between BMI and mortality [29], which is known to exist in healthy subjects, shifts to the right in CHF, resulting in a higher optimal BMI with regard to survival. In severe CHF, high fat stores (high BMI), may indicate preserved metabolic efficiency and/or energetic reserves. More research should be done to clarify this paradox.

$\beta$-blockers as well as diuretics have long-term metabolic effects including an effect on IS. The effect varies among the different kinds of $\beta$-blockers and diuretics $[30,31]$. ACE-inhibitors are known to have a positive effect on IS while AT-II blockers show controversial results with respect to IS [32]. Unfortunately, the diversity in medication use in our group of patients was large and consequently, the subgroups were very small. Therefore, we could not analyse the effect of medication use in detail. The present study showed, that no differences in IS were found between patients who used $\beta$-blockers and the ones who did not, not even when users of nonselective B-blockers (which have been shown to induce beneficial effects on IS [31]) were analysed separately. Consequently, adding 'use of $\beta$-blockers' to the model did not result in an increase in explained variance of IS.

In the present study, BMI, smoking, age, DPA and LVEF seemed to be the most important predictors of IS. From the result that BMI could be replaced by FM or percentage body fat in the model but not by FFM, we may conclude that in our patients, IS was not determined by FFM but by total body fat. The fact that BMI and age are among the most important predictors of IS, is in agreement with studies in healthy subjects $[13,17]$.

Remarkably, in our study, smokers had a higher IS than non-smokers. In healthy subjects, smoking is associated with decreased insulin sensitivity [10], presumably because the sympathetic nervous system is activated by smoking [33]. In addition, smoking is known to be associated with elevated plasma leptin levels [34]. Leptin is negatively associated with IS and has been shown to be an independent predictor of IS in CHF patients [35]. However, our finding, of a higher IS in smokers, is in agreement with Mooy et al. [36]. Since smoking and alcohol consumption are closely related [37], a potential explanation might be that there are more (moderate) alcohol consumers in the group of smokers than in the non-smoking group. Light-to-moderate alcohol intake is associated with enhanced insulin sensitivity [38]. Since we do not have data on alcohol intake in our patient group, we are not able to verify this suggestion. The contribution of each independent variable is evaluated, with the influence of other independent variables controlled. The effect of smoking that is shown in the model (Fig. 1), is an effect that persists after correction for BMI. This strengthens the idea that smoking is not only related to IS via BMI but also via the other aforementioned mechanisms.

Etiology of heart failure was an additional determinant of IS. This is in agreement with the study of Swan et al. [6], in which a higher IS was found in patients with ischemic etiology of heart failure.

The DPA-score in the present study was relatively low compared to the healthy, elderly subjects studied in the validation study for the questionnaire [24]. Even though our study group was younger $(61 \pm 9$ as opposed to $71 \pm 5)$ and consisted only of men, whereas in the validation study both women and men participated. As DPA decreases with age and men tend to be more physically active than women [39], we conclude that DPA score of our patients is indeed lower than of healthy subjects, probably as a result of their disease.

In contrast to DPA, peak $\mathrm{VO}_{2}$ did not contribute to the variance in IS. This finding may relate to the possibility that the DPA score provides supplemental information about the actual exercise tolerance of CHF patients. Peak $\dot{V}_{\mathrm{O}_{2}}$ refers to activity with maximum intensity, which is a rather uncommon situation in daily life. This is supported by the fact that peak $\dot{V}_{\mathrm{O}_{2}}$ related to DPA but most strongly to the sports component of the DPA-score. While IS showed the strongest relationship with the household score.

The present study did not show a relationship of peak $\dot{V} \mathrm{O}_{2}$ with IS. In healthy subjects, peak $\dot{V}_{\mathrm{O}_{2}}$ is strongly associated with IS [17]. Two studies, focussing on the relationship between peak $\dot{V}_{2}$ and IS in CHF patients, have reported a positive bivariate relationship between 
peak $\dot{V}_{\mathrm{O}_{2}}$ and IS $[6,15]$. The methodological differences in measuring IS and exercise tolerance, and differences in medication use, may explain the lack of agreement between these studies and ours.

The residual IS variance that remains unaccounted for (40\%) after modelling the study variables, implies that other factors are involved. Among these, the already mentioned leptin, nutrition, muscle fibre type distribution and components of the anabolic/catabolic balance are of interest. In a small subgroup of our patients, nutritional intake was studied in relation to IS. Daily energy intake, as well as intake of fat and sugars, were inversely related to IS [40]. It is known that high fat diets result in impaired glucose tolerance and elevated plasma triglyceride levels. The latter is associated with decreased IS [6], but this could not be confirmed in the present study. Impaired glucose tolerance is related to decreased insulin-stimulated glucose metabolism. Changes in the fatty acid composition of the membrane induced by dietary fat modification related to this [41]. In CHF patients, muscle fibre type distribution was found to shift towards more type II fibres, probably as a result of apoptosis [42]. This will decrease IS, since type II fibres are less insulin sensitive than type I fibres [43]. In CHF, the anabolic/catabolic balance is disturbed [5], and it is plausible that this affects IS. Finally, IS is affected by high levels of TNF- $\alpha$, which have been reported to be increased in CHF [5]. TNF- $\alpha$ is a circulating cytokine, which, after interacting with its membrane receptor, leads to serine phosphorylation of IRS-1. This serine-phosphorylated IRS-1 decreases insulin receptor tyrosine kinase activity, and thus impairs insulin signalling [44].

In conclusion, IS in CHF was determined by BMI, smoking, age, DPA and LVEF and to a lesser extent by etiology of heart failure. Use of $\beta$-blockers, peak $\dot{V}_{\mathrm{O}_{2}}$ parameters of the lipoprotein profile did not relate to IS.

Studies in which neurohormonal factors and nutrition are also included may shed light on the complex role of IS in CHF.

\section{Acknowledgments}

The authors would like to thank Dr E. Bol for statistical advice and Prof. Dr P.G. Hugenholz for critical reading of the manuscript. This study was funded by: Netherlands Heart Foundation (grant 98.125), Sorbo Heart Foundation, Foundation for Research on Cardiovascular Disease, Eemland Foundation for Scientific Research (Amersfoort, The Netherlands).

\section{References}

[1] Sullivan MJ, Higginbotham MB, Cobb FR. Exercise training in patients with severe left ventricular dysfunction. Circulation 1988;78:506-15.
[2] The European Society of Cardiology. Overview of studies of exercise training in chronic heart failure: the need for a prospective randomized multicentre European trial. Eur Heart J 1998;19:830-41.

[3] Coats AJS. The 'muscle hypothesis' of chronic heart failure. J Mol Cell Cardiol 1996;28:2255-62.

[4] Drexler H, Riede U, Münzler T, König H, Funke E, Just H. Alterations of skeletal muscle in chronic heart failure. Circulation 1992;85:1751-9.

[5] Berry C, Clark AL. Catabolism in chronic heart failure. Eur Heart J 2000;21:521-32.

[6] Swan JW, Anker SD, Walton C, et al. Insulin resistance in chronic heart failure: relation to severity and etiology of heart failure. J Am Coll Cardiol 1997;30:527-32.

[7] Poole-Wilson PA, Ferrari R. Role of skeletal muscle in the syndrome of chronic heart failure. J Mol Cell Cardiol 1996;28:2275-85.

[8] Scherrer U, Stevenson JC. Insulin as a vascular and sympathoexcitatory hormone. Circulation 1997;96:4104-12.

[9] Parsonage WA, Hetmanski WA, Cowley AJ. Beneficial haemodynamic effects of insulin in chronic heart failure. Heart 2001;85:508-13.

[10] Facchini FS, Hollenbeck CB, Jeppesen J, Chen YDI, Reaven GM. Insulin resistance and cigarette smoking. The Lancet 1992;339:1128-30.

[11] Firth R, Bell P, Rizza R. Insulin action in non-insulin-dependent diabetes mellitus: the relationship between hepatic and extra hepatic insulin resistance and obesity. Metabolism 1987;36:1091-5.

[12] Ferranini E, Natali A, Bell P, Cavello-Perin P, Lalic N, Mingrone G. Insulin resistance and hypersecretion in obesity. J Clin Invest 1997;100:1166-73.

[13] Muller DC, Elahi D, Tobin JD, Andres R. The effect of age on insulin resistance and secretion: a review. Semin Nephrol 1996;16:289-98.

[14] Koivisto VA, Yki-Järvinen H, DeFronzo RA. Physical training and insulin sensitivity. Diabetes/Metab Rev 1986;1:445-81.

[15] Pietilä M, Malminiemi K, Huupponen R, et al. Celiprolol augments the effect of physical exercise on insulin sensitivity and serum lipid levels in chronic heart failure. Eur $\mathrm{J}$ Heart Failure 2000;2:81-90.

[16] Zonderland ML, Dubbeldam S, Erkelens DW, van Haeften TW. Lower $\beta$-cell secretion in physically active first-degree relatives of type 2 diabetes patients. Metabolism 2000;49:1-7.

[17] Clausen JO, Borch-Johnsen K, Ibsen H, et al. Insulin sensitivity index, acute insulin response, and glucose effectiveness in a population-based sample of 380 young healthy caucasians. Analysis of the impact of gender, body fat, physical fitness and life-style factors. J Clin Invest 1996;98:1195-209.

[18] Schiller MB, Acquatella A, Ports TA. Left ventricular volume from paired biplane two-dimensional echocardiography. Circulation 1979;60:547-55.

[19] Durnin JVGA, Womersley L. Body fat assessed from total body density and its estimation from skinfold thickness: measurements on 481 men and women aged from 16 to 72 years. Br J Nutr 1974;32:77-97.

[20] Dasgupta S, Hazra SC. The utility of waist circumference in assessment of obesity. Indian J Public Health 1999;43:132-5.

[21] DeFronzo RA, Tobin JD, Andres R. Glucose clamp technique: a method for quantifying insulin secretion and resistance. Am J Physiol 1979;237:E214-E223.

[22] American Diabetes Association. Consensus development conference on insulin resistance. Diabetes Care 1998;21:310-4.

[23] Matthews DR, Hosker JP, Rydenski AS, Naylor BA, Treacher DF, Turner RC. Homeostasis model assessment: insulin resis- 
tance and $\beta$-cell function from fasting plasma glucose and insulin concentrations in man. Diabetologia 1985;412-9.

[24] Voorrips LE, Ravelli ACJ, Dongelmans PCA, Deurenberg P, van Staveren WA. A physical activity questionnaire for the elderly. Med Sci Sports Exerc 1991;23:974-9.

[25] American Diabetes Association. American Diabetes Association: report of the expert committee on the diagnosis and classification of diabetes mellitus. Diabetes Care 1997;20:1183-97.

[26] Jones NL. Clinical exercise testing. Philadelphia: WB Saunders Company, 1988. p. 305-5.

[27] Krauss RM, Winston M. Obesity: impact on cardiovascular disease. Circulation 1998;98:1472-6.

[28] Horwich TB, Fonarow CG, Hamilton MA, MaxLellan WR, Woo MA, Tillisch JH. The relationship between obesity and mortality in patients with heart failure. J Am Coll Cardiol 2001;38:789-95.

[29] Allison DB, Faith MS, Heo M, Kotler DP. Hypothesis concerning the U-shaped relation between body mass index and mortality. Am J Epidemiol 1997;146:339-49.

[30] Lind L, Pollare T, Berne C, Lithell H. Long-term metabolic effects of antihypertensive drugs. Am Heart J 1994;128:117783.

[31] Jacob S, Rett K, Henriksen E. Antihypertensive therapy and insulin sensitivity: do we have to redefine the role of betablocking agents? Am J Hypertension 1998;11:1258-65.

[32] Bernobich E, de Angelis L, Lerin C, Bellini G. The role of the angiotensin system in cardiac glucose homeostasis. Therapeutic implications. Drugs 2002;62:1295-314.

[33] Grassi G, Seravalle G, Calhoun DA, et al. Mechanisms responsible for sympathetic activation by cigarette smoking in humans. Circulation 1994;90:248-53.

[34] Eliasson B, Smith U. Leptin levels in smokers and long-term users of nicotine gum. Eur J Clin Invest 1999;29:145-52.
[35] Doehner W, Godsland IF, Egerer K, et al. Insulin resistance in moderate chronic heart failure is related to hyperleptinaemia, but not to norepinephrine or TNF-alpha. Int $\mathrm{J}$ Cardiol 2002;83:73-81.

[36] Mooy JM, Grootenhuis PA, de Vries H, Bouter LM, Kostense PJ, Heine RJ. Determinants of specific serum insulin concentrations in a general caucasian population aged 50-74 years (the Hoorn study). Diabetic Med 1998;15:45-52.

[37] Ma J, Betts NM, Hampl JS. Clustering of lifestyle behaviours: the relationship between cigarette smoking, alcohol consumption and dietary intake. Am J Health Promotion 2000;15:10717.

[38] Facchini FS, Chen YDI, Reaven GM. Light-to-moderate alcohol intake is associated with enhanced insulin sensitivity. Diabetes Care 1994;17:115-9.

[39] Hivensalo M, Lampinen P, Rantanen T. Physical exercise in old age: an 8-year follow-up study on involvement, motives, and obstacles among persons age 65-84. J Aging Phys Activity 1998;6:157-68.

[40] Zonderland ML, Senden PJ, Sabelis LWE, Calmaz R, Huisveld IA, Mosterd WL. Insulin sensitivity is related to nutritional intake in chronic heart failure. Suppl Med Sci Sports Exerc 2001;33:S267-S267 (Abstract).

[41] Lichtenstein AH, Schwab US. Relationship of dietary fat to glucose metabolism. Atherosclerosis 2000;150:227-43.

[42] Adams V, Jiang H, Yu J, et al. Apoptosis in skeletal myocytes of patients with chronic heart failure is associated with exercise intolerance. J Am Coll Cardiol 1999;33:959-65.

[43] Rodnick KJ, Piper RC, Slot JW, James DE. Interaction of insulin and exercise on glucose transport in muscle. Diabetes Care 1992;15:1679-89.

[44] Trischitta V, Frittita L, Vigneri R. Early molecular defects in human insulin resistance: studies in healthy subjects with low insulin sensitivity. Diabetes/Metab Rev 1997;13:147-62. 